\title{
Prevalence of psychosexual problems in patients attending a genitourinary clinic
}

\author{
K SLATFORD AND C CURRIE \\ From the Department of Genitourinary Medicine, Royal Infirmary, Edinburgh
}

SUMMARY The prevalence of self reported psychosexual problems in 265 men and 160 women who attended the genitourinary clinic at this hospital was assessed. Twenty-six $(10 \cdot 6 \%)$ men and $13(9.0 \%)$ women had sexual problems either as an individual or within their regular relationship. The highest prevalence of problems was in married or cohabiting women and men, both homosexual and heterosexual, over 30.

\section{Introduction}

Psychosexual problems in patients attending genitourinary clinics have been recognised by doctors and health advisers, but are often either ignored or dealt with in a perfunctory manner as no effective method of treatment was thought to be available. In addition, the doctor or health adviser may have had no training in psychosexual medicine and little experience in dealing with patients with psychosexual problems. Effective methods of treatment are now available, ${ }^{1}$ and their techniques have been successfully modified by various workers ${ }^{2}{ }^{3}$ to a form suitable for patients attending busy NHS clinics. We suspected that there was a need for psychosexual counselling in patients attending the department of genitourinary medicine in Edinburgh. This suspicion was supported by a survey at a family planning clinic in Edinburgh, which showed that $12 \%$ of attenders reported a sexual problem and a further $8 \%$ were uncertain. ${ }^{4}$ The study reported here was carried out to ascertain the prevalence of psychosexual problems in people attending the genitourinary clinic and to gauge the attitudes of patients to discussing sexual problems either at the clinic or at a proposed separate sexual problem clinic within the department.

\section{Patients and methods}

The study was carried out at the clinic of the department of genitourinary medicine at this hospital, which serves Edinburgh, the Lothians, and the borders. Consecutive new and "new return"

Address for reprints: Dr K Slatford, Department of Genitourinary Medicine, Royal Infirmary, Edinburgh EH3 9YW

Accepted for publication 8 April 1984 patients (those who had not attended for at least three months) were considered for inclusion in the study. Those excluded were patients who did not wish to take part and those whose participation the doctor judged to be inappropriate-for example, patients who were drunk, did not speak English, or were too anxious. Informed consent was obtained from each participant. An explanatory leaflet and a questionnaire (figure) were given to patients after they had been examined and their histories taken and before the results of microscopy were known. Each patient was left alone to complete the questionnaire, which the doctor then checked. If a patient reported a sexual problem and wished to have help, the nature of the problem was assessed and dealt with either by brief counselling or by referral to the authors for further assessment. The questionnaire was anonymous.

STATISTICAL ANALYSIS

The significance of differences between those with and those without problems was determined using the $\chi^{2}$ test for categorised variables and the Wilcoxon rank sum test for age.

\section{Results}

Of the 425 patients $(265(62 \cdot 4 \%)$ men and $160(37 \cdot 6)$ women) considered for inclusion in the study, $36(20$ $(7 \cdot 5 \%)$ men and $16(10 \%)$ women) were excluded; 14 did not wish to participate and 22 were considered to be inappropriate for the study. Table I shows the sex, age, marital status, and sexual preference of the 389 patients completing the questionnaire. Almost three quarters of both men and women were between 20 and 34 years old and most were single. Of the 245 men, $139(56 \cdot 7 \%)$ had a regular sexual partner, 50 
Please tick the appropriate box.

(1) What is your age?

Under 16
$25-29$
40 or over
Are you
Single?
Divorced?
Are you homosexual?
Do you have a regular partner?
Would you confide in a doctor or counsellor who works in the clinic if you had a sexual problem?
Do you think you have a sexual problem of any kind?
If you have a regular partner

(a) Do you live with your partner?

(b) Do you think your partner has a sexual problem?

(8) Would you be interested in attending a separate sexual problems clinic within this department if you or your partner had a sexual problem?

(9) If yes to question (8) what time would you prefer such a clinic to operate?

IF YOU WOULD I.IKE HEI.P WITH A PARTICULAR PROBLEM, PI.EASE COMPI.ETE TEAR OFF SI.IP AND SPEAK TO THE DOCTOR.

FICiURE Questionnaire completed by 389 people attending the genitourinary clinic, Rolal Infirmary, Edinburgh.

TABLE I Demographic characteristics of 389 people who completed questionnaire concerning sexual problems

\begin{tabular}{lcc}
\hline & $\begin{array}{l}\text { No (\%) of } \\
\text { men }(n=245)\end{array}$ & $\begin{array}{c}\text { No (\%) of } \\
\text { women }(n=144)\end{array}$ \\
\hline Age (years): & & 1 \\
under 16 & 0 & $(0 \cdot 7)$ \\
$16-19$ & $18(7 \cdot 4)$ & $28(19 \cdot 4)$ \\
$20-24$ & $68(27 \cdot 8)$ & $45(31 \cdot 3)$ \\
$25-29$ & $63(25 \cdot 7)$ & $33(22 \cdot 9)$ \\
$30-34$ & $45(18 \cdot 4)$ & $26(18 \cdot 1)$ \\
$35-39$ & $20(8 \cdot 2)$ & $6(4 \cdot 2)$ \\
40 or over & $31(12 \cdot 7)$ & $5(3 \cdot 5)$ \\
Marital status: & $163(66 \cdot 5)$ & $88(61 \cdot 1)$ \\
Single & $50(20 \cdot 4)$ & $23(16 \cdot 0)$ \\
Married & $16(6 \cdot 5)$ & $9(6 \cdot 3)$ \\
Separated & $16(6 \cdot 5)$ & $24(16 \cdot 7)$ \\
Divorced & 0 & 0 \\
$\quad$ Widowed & & \\
Sexual preference: & $212(86 \cdot 5)$ & $143(99 \cdot 3)$ \\
Heterosexual & $33(13 \cdot 5)$ & $1(0 \cdot 7)$ \\
Homosexual & &
\end{tabular}

$(20 \cdot 4 \%)$ were married, and $20(8 \cdot 2 \%)$ were cohabiting with their partners. Of the 144 women, $108(75 \%)$ had a regular sexual partner, $23(16 \%)$ were married, and $18(12 \cdot 5 \%)$ cohabiting. Thirty three $(13 \cdot 5 \%)$ of the men said they were homosexual; $14(42 \cdot 4 \%)$ of them had a regular partner and five $(15 \cdot 2 \%)$ were living with their partners.

The study population was compared statistically with the total number of people attending the clinic in 1981 and was typical of that year except that the men were slightly older (median age in study population was $22 \cdot 9$ years compared with $21 \cdot 2$ years in the total clinic population in 1981) and the percentage of homosexuals was greater $(13.5 \%$ in the study population compared with $8.7 \%$ in the total clinic population in 1981).

\section{SELF REPORTED SEXUAL PROBLEMS}

Table II shows the demographic details of patients reporting sexual problems compared with those with no sexual problems. Twenty one $(8 \cdot 6 \%)$ men reported having a sexual problem, 20 confided in a doctor at the clinic and 19 were willing to attend a separate clinic. Eight $(5 \cdot 6 \%)$ women reported having a sexual problem, seven confided in a doctor at the clinic, and seven were willing to attend a separate clinic. When the sexual problems of patients' partners were considered too, $26(10 \cdot 6 \%)$ men and $13(9 \cdot 0 \%)$ women had a sexual problem in their relationship.

Ninety three per cent of the men and $87 \%$ of the women said they would confide in a doctor at the clinic if they had a sexual problem. Seventy six per cent of the men and $79 \%$ of the women said they would attend a separate sexual problems clinic within the department of genitourinary medicine.

\section{PATIENTS REPORTING PROBLEMS COMPARED} WITH THOSE REPORTING NONE

Significant differences in age between those reporting problems and those not doing so were found in heterosexual men $(\mathrm{p}<0.001)$ and homosexual men $(\mathrm{p}<0 \cdot 05)$; those reporting problems being older (over 30 ) in both cases. The difference in age for women was not significant. Women with problems differed significantly $(p<0.05)$ from those with none in marital status and in the proportion who had a regular partner living with them. Those with 
TABLE II Comparison of demographic details of patients with sexual problems and those with no sexual problems

\begin{tabular}{|c|c|c|c|c|c|c|}
\hline & $\begin{array}{l}\text { Women ( } n \\
\text { Problems } \\
\text { / } n=8\end{array}$ & $\begin{array}{l}\text { None } \\
(n=136)\end{array}$ & $\begin{array}{l}\text { Heterosex } \\
\text { Problems } \\
(n=16)\end{array}$ & $\begin{array}{l}\text { nen }(n=212) \\
\text { None } \\
(n=196)\end{array}$ & $\begin{array}{l}\text { Homosexua } \\
\text { Problems } \\
(n=5)\end{array}$ & $\begin{array}{l}\text { nen }(n=33) \\
\text { None } \\
(n=28)\end{array}$ \\
\hline \multicolumn{7}{|l|}{ Age (years): } \\
\hline Under 16 & 0 & 1 & 0 & 0 & 0 & 0 \\
\hline $16-19$ & 0 & 28 & 1 & 17 & 0 & 0 \\
\hline $20-24$ & 3 & 43 & $i$ & 61 & 0 & 6 \\
\hline $25-29$ & 2 & 30 & 0 & 47 & 1 & 15 \\
\hline $30-34$ & 2 & 24 & 6 & 32 & 2 & 5 \\
\hline $35-39$ & 0 & 6 & 1 & 17 & 1 & 1 \\
\hline 40 or over & 1 & 4 & 7 & 22 & $i$ & 1 \\
\hline \multicolumn{7}{|c|}{ Marital status: } \\
\hline Single & 3 & 85 & 7 & 126 & 3 & 27 \\
\hline Married & 3 & 19 & 6 & 43 & 1 & 0 \\
\hline Separated & 1 & 9 & 2 & 13 & $i$ & 0 \\
\hline Divorced & $i$ & 23 & 1 & 14 & 0 & 1 \\
\hline Widowed & 0 & 0 & 0 & 0 & 0 & 0 \\
\hline \multicolumn{7}{|c|}{ Regular partner: } \\
\hline Yes & 5 & 102 & 9 & 116 & 1 & 13 \\
\hline No & 3 & 34 & 7 & 80 & 4 & 15 \\
\hline \multicolumn{7}{|c|}{ Living with partner: } \\
\hline Yes & 5 & 35 & 6 & 59 & 1 & 4 \\
\hline No & 0 & 67 & 3 & 57 & 0 & 9 \\
\hline
\end{tabular}

problems were more likely to be married or to be living with their partner. No other significant differences were found.

TYPES OF SEXUAL PROBLEMS

A detailed assessment of the types of self reported sexual problems seen in clinic attenders was not possible as some were inadequately assessed at their first attendance and subsequently lost to follow up. A clearer picture of the types of problems seen will emerge from prospective study of patients requiring either brief counselling or referral for psychosexual assessment and therapy. We hope to do this in the near future. Among the problems assessed were, in men: premature ejaculation, erectile difficulty, loss of interest in sexual intercourse, and various psychomatic problems, such as anxiety about size of penis. Some homosexual men were assessed as having a problem of sexual identity. In women, lack of interest or enjoyment in sexual intercourse was common. Two couples have started therapy as a result of this study.

All patients with a psychosexual problem that had not been satisfactorily dealt with at presentation were sent a letter offering an appointment for further assessment, with their partner if appropriate, at a separate sexual problem clinic set up outside the usual genitourinary clinic times. Response to these letters was poor.

\section{Discussion}

Of the patients surveyed, $10 \%$ reported a sexual problem either as an individual or within their regular relationship, and almost all patients with a sexual problem wanted to confide in their clinician at the outpatient clinic or to attend a separate sexual problems clinic within the department. As the characteristics of the study population were comparable with those of the clinic attenders in 1981, we estimate that in that year about 784 people had a sexual problem. It would seem that this is a genuine health need in clinic attenders, which is not met.

The prevalence of psychosexual problems in our population is similar to that estimated by Begg et al at an Edinburgh family planning clinic. ${ }^{4}$ It is likely that our findings are also similar to those of Swan and Wilson, who found that $25 \%$ of "first attenders" at a psychiatric clinic reported sexual or marital difficulties without attempting to differentiate between these variables. ${ }^{5}$ Our estimate of prevalence, however, seems to be lower than that of Catalan et al, who found that one fifth of men and one quarter of women attending a clinic for sexually transmitted diseases in Oxford were experiencing sexual dysfunction..$^{5}$ These higher figures could be explained by the different interviewing techniques, as a structured interview was used in Oxford. Such detailed assessment is likely to be more objective and thorough than a questionnaire technique. Patients' perception of what constitutes sexual dysfunction may vary from Oxford to Edinburgh, however, or indeed the prevalence of sexual problems in Edinburgh may be less than in Oxford. Certainly the authors considered that the patients' subjective perception of their sexual functioning was crucial in determining their presentation. Self reported sexual problems will thus accurately reflect health demand 
in our clinic population. These comparisons suggest that our findings are broadly similar to those of other clinic populations.

Health care professionals in genitourinary clinics should be aware of psychosexual problems in their patients and how they might be managed. Most problems can be helped effectively by simple counselling; those requiring more time can be managed at a separate sexual problems clinic or by appropriate referral. People with a significantly higher "risk" of having a sexual problem were married or cohabiting women and men over 30 , both homosexual and hetrosexual.

We thank the staff of the department of genitourinary medicine for their cooperation.

\section{References}

1. Masters WH, Johnson VE. Human sexual inadequacy. London: Churchill, 1970.

2. Kaplan HS. The new sex therapy. New York: Brunner/Mazel, 1974.

3. Bancroft J. Human sexuality and its problems. Edinburgh: Churchill Livingstone, 1983.

4. Begg A, Dickerson $M$, Loudon MB. Frequency of selfreported sexual problems in a family planning clinic. Journal of Family Planning Doctors 1976;2:41-8.

5. Swan M, Wilson LJ. Sexual and marital problems in a psychiatric outpatient population. $B r J$ Psychiatry 1979; 135: $310-4$.

6. Catalan J, Bradley M, Gallwey J, Hewton K. Sexual dysfunction and psycniatric morbidity in patients attending a clinic for sexually transmitted disease. Br J Psychiatry 1981; 138:292-6. 